\title{
ECOFEMINISMO: ANÁLISE DA MULHER COMO VETOR DE SUSTENTABILIDADE
}

\author{
Flavia Piccinin Paz* \\ Marcelo Wordell Gubert** \\ João Edmilson Fabrini ***
}

\begin{abstract}
RESUMO: O artigo visa o estudo do empoderamento da mulher, na finalidade de que através do conhecimento da sua relação com o ambiente estas venham a desenvolver atividades de sustentabilidade. Com subsídio teórico em Ulrich Beck, e artigos científicos, através do método dedutivo, analisou o ecofeminismo, sua origem e correntes, propondo uma compreensão do princípio da precaução e da teoria do risco. Através do método hipotéticodedutivo, focalizou na análise do empoderamento da mulher como vetor de sustentabilidade. Concluiu que a mulher é meio natural de sustentabilidade, sendo real aplicação do princípio da precaução, agindo como meio de prevenção ao dano ambiental.
\end{abstract}

PALAVRAS-CHAVE: Empoderamento; Precaução; Dano; Mulher; Sustentabilidade

\section{ECOFEMINISM: ANALYSIS OF WOMEN AS A VECTOR OF SUSTAINABILITY}

ABSTRACT:The article aims to study the empowerment of women, in order that through the knowledge of their relationship with the environment they will develop sustainability activities. With theoretical support in Ulrich Beck, and scientific articles, through the deductive method, he analyzed ecofeminism, its origin and currents, proposing an understanding of the precautionary principle and the risk theory. Through the hypotheticaldeductive method, it focused on the analysis of women's empowerment as a vector of sustainability. He concluded that women are a natural means of sustainability, being a real application of the precautionary principle, acting as a means of preventing environmental damage.

KEYWORDS: Empowerment; Precaution; Damage; Women; Sustainability

\footnotetext{
* Doutoranda em Direito pela Universidade Estadual do Oeste do Paraná - Unioeste (2019), Mestre em Direito Processual e Cidadania na Universidade Paranaense - UNIPAR (2012), advogada e professora universitária. flavia@gubertepaz.com https://orcid.org/0000-0002-8179-8426

* Doutorando em Direito pela Universidade de Marilia (2019), Mestre em Direito Processual e Cidadania na Universidade Paranaense - UNIPAR (2010), advogado e professor universitário. marcelo@gubertepaz.com https://orcid.org/0000-0002-2499-7461

** Pós-doutor, doutor, mestre e graduado em Geografia. Professor de graduação e pós-graduação da Universidade Estadual do Oeste do Paraná - Unioeste e Universidade Federal da Grande Dourados UFGD. joaofabrini@gmail.com https://orcid.org/0000-0001-9562-0226 (orientador)
} 


\section{INTRODUÇÃO}

O presente artigo tem o intuito de estudar o ambiente, sob o aspecto sociológico e filosófico, utilizando como ponto de partida para o estudo o ecofeminismo e os fatores que motivam as mulheres a protegerem o ambiente rural familiar.

O ecofeminismo surge a partir de uma questão de gênero, buscando analisar a submissão da mulher frente ao patriarcado no meio rural, o qual possui uma visão de exploração total da propriedade e de divisão de tarefas rurais, de modo a deixar a mulher em segundo plano.

Traz a visão de empoderamento da mulher campesina, fazendo com que esta venha a ser detentora de "poder de conhecimento".

Busca-se deste modo, identificar se o empoderamento da mulher, no âmbito da agricultura familiar, seria forma de precaução ao dano ambiental, por meio da formação de uma consciência ecológica e sustentável, e por meio disso, analisar quais são as contribuições que o ecofeminismo traz, de forma teórica e pratica, buscando desenvolver propostas de mudanças nas relações de gênero, com a finalidade de evolução para outro paradigma produtivo, mais sustentável, mais equilibrado.

Para construção do estudo pretende analisar o ecofeminismo, suas principais correntes buscando identificar sua contribuição à conservação ambiental e a relação entre o gênero feminino e a natureza; destacar os fatores que motivam as mulheres a proteger o ambiente rural familiar e avaliar o empoderamento no âmbito da economia familiar como medida de sustentabilidade; bem como, comparar se as medidas de sustentabilidade tomadas, são oriundas de conhecimento da legislação ou pré-disposição natural e identificar se o empoderamento da mulher, no âmbito da agricultura familiar, é forma de precaução ao dano ambiental por meio de atividades sustentáveis.

Para o desenvolvimento do presente estudo será utilizado à pesquisa bibliográfica, exploratória descritiva, onde serão analisados artigos, doutrinas, com viés descritivo e análise documental. Será utilizado o método qualitativo. Sendo a pesquisa do tipo exploratório, com a finalidade de explorar todos os campos com possibilidade de retirar informações necessárias para obtenção de resultados satisfatórios. 
Ao analisar a finalidade de uma pesquisa, Antônio Carlos Gil observa que "uma pesquisa tem por finalidade decorrer de razões de ordem intelectual, quando baseadas no desejo de conhecer pela simples satisfação para agir" (GIL, 2002, p.42).

Deste modo, como já mencionado, esta pesquisa adota o método dedutivo e caracteriza-se como bibliográfica, de natureza qualitativa e exploratória, nível descritivo, como também o método hipotético-dedutivo.

\section{O ECOFEMINISMO}

Questões de ética, ecologia e espiritualidade são recorrentes nos debates e foco de discussão de grandes pensadores, em especial Boff (2009, p. 18), que afirma que "a partir da visão verdadeiramente holística (globalizadora), compreendemos melhor o ambiente e a forma de tratá-lo com respeito (ecologia ambiental)".

Dentro da visão holística expõe Boff (2009, p.22) a necessidade de superar o antropocentrismo, em favor do cosmocentrismo e de cultivar uma intensa vida espiritual.

Nessa vertente nasce o ecofeminismo, que tem por base a soma do feminismo com o ativismo ecológico, movimento pinçado em várias correntes sendo elas, liberal, marxista, socialista e ecofeminista.

Em que pese ter surgido na década de 1970, o movimento ecofeminista ganhou repercussão e visibilidade com a atuação das mulheres frente a desastres ecológicos, como o movimento Chipko ${ }^{4}$ na índia, e o avanço de usinas nucleares5 nos Estados Unidos. (BONI, 2012)

Apresenta como conceito de ecofeminismo, a soma das narrativas de Puleo (2011); Warren, (2003); Siliprandi, (2000); Angelin (2014) e Boni (2012), da qual se pode compreender que o ecofeminismo, tem por base a soma do feminismo com o ativismo ecológico, defendendo que as mulheres possuem uma relação de cuidado com a saúde e com a natureza, pois são geradoras de vida, e associa a dominação das mulheres a dominação da natureza.

\footnotetext{
${ }^{4}$ Em 1974 no Norte da Índia, aproximadamente trinta mulheres abraçaram-se as árvores para impedir que fossem derrubadas.

${ }^{5} \mathrm{Na}$ cidade de Love Canal, no final da década de 1970 a população liderada por uma mulher lutou contra o Estado. Incialmente o motivo era o forte odor que atingia a cidade e o alto índice de doenças que acometiam as crianças. Após a mobilização foi descoberto que a cidade havia sido construída sobre um deposito de lixo químico.
} 
Assim, o ecofeminismo origina-se com a premissa do reconhecimento do vínculo entre a mulher e a natureza, estando estas ligadas pela opressão e exploração.

A filosofia ecofeminista, portanto, baseia-se: 1) no feminismo; 2) na ecologia e no ambientalismo; e 3) na filosofia, com sua análise dos sistemas humanos de dominação injustificada, o que a autora chamada de "ismos" de dominação. Considera-se que tal dominação não é justificada, tampouco inevitável. O feminismo, um "ismo" de libertação, refere-se ao uso da análise de sexo/gênero como ponto de partida para criticar os "ismos de dominação". A ecologia e o ambientalismo, por sua vez, usam insights sobre as interações humano-natureza, em sua teoria e prática. Como filosofia, usa a análise conceitual e a justificação argumentativa. (ROSENDO, 2012, p. 62)

Contudo, dentro do próprio ecofeminismo há diferenças pontuais entre "filosofia ecofeminista" e "feminismo ecológico", o primeiro retrata a relação filosófica entre mulher e natureza, já a feminismo ecológico, trata da dominação da mulher e sua relação com a dominação da natureza. (WARREN, 2003, p. 12-13).

A partir de Warren (2003), em sua obra Filosofías ecofeministas pode ser definido dez conexões necessárias para entender a ideia central do ecofeminismo. Tais conexões são defendidas e sustentadas por teóricos distintos, porém, muitas se relacionando entre si.

O termo ecofemismo tem sua origem com a escritora francesa Françoise D’Éaubonne (1920-2005), em seu ensaio literário Le féminisme ou lamort, lançado em 1974. (SILIPRANDI, 2000. p. 87). Nesta obra, a autora sugere que as mulheres, assim como a natureza, são dominadas pelo patriarcado, que se apropria da fecundidade - da mulher, e da fertilidade - da natureza.

Deegan e Podeschi (apud ROSENDO, 2012, p. 21) afirmam que o ecofeminismo "enfatiza a interconexão entre vida, natureza e ambiente com a visão de mundo das mulheres e a capacidade reprodutiva", além de "examinar a relação entre a opressão social das mulheres e a exploração da natureza como duas faces do controle machista."

Pontua-se desde modo que, na visão do ecofeminismo, reconhece-se que a natureza está associada com o feminino, vinculando a desvalorização da natureza com a desvalorização das mulheres através da exploração e do abuso.

Rosendo (2012, p. 29) em sua obra, sensível ao cuidado, traz a visão de Karen J. Warren, filósofa ecofeminista, que se manifesta no sentido de que o ecofeminismo surge, trazendo princípios baseados no reconhecimento de que existem vínculos importantes entre a 
opressão das mulheres e da natureza, e as razões pelas quais ambas são consideradas inferiores é tema central na busca por justiça e igualdade.

Rosendo, (2012, p. 32) estabelece um vínculo entre o orgânico e o científico ao afirmar que a feminização da natureza é um fenômeno ligado à ideia de que a natureza é algo vulnerável e que pode ser abusada, cabendo, portanto, às mulheres, também vulneráveis, cuidarem do orgânico; economicamente e socialmente menos valorizado do que as funções relacionadas à revolução científica.

Assim, o ecofeminismo origina-se com a premissa do reconhecimento de um vínculo entre a mulher e a natureza, estando estas ligadas pela opressão e exploração.

A filosofia ecofeminista, portanto, baseia-se: 1) no feminismo; 2) na ecologia e no ambientalismo; e 3) na filosofia, com sua análise dos sistemas humanos de dominação injustificada, o que a autora chamada de "ismos" de dominação. Considera-se que tal dominação não é justificada, tampouco inevitável. O feminismo, um "ismo" de libertação, refere-se ao uso da análise de sexo/gênero como ponto de partida para criticar os "ismos de dominação". A ecologia e o ambientalismo, por sua vez, usam insights sobre as interações humano-natureza, em sua teoria e prática. Como filosofia, usa a análise conceitual e a justificação argumentativa. (ROSENDO, 2012, p. 62)

As correntes ecofeministas, difundidas na "ECO-92", são classificadas em ecofeminismo espiritualista do Terceiro Mundo, ecofeminismo clássico e ecofeminismo construtivista.

O ecofeminismo espiritualista do Terceiro Mundo possui sua origem nos países do sul e influenciado, tendo por referencial Vandana Shiva, autora da obra Staying Alive: Women, Ecologyand Survival, em 1988, defendendo que o desenvolvimento da sociedade gera um processo de violência contra a mulher e o ambiente, tendo suas raízes nas concepções patriarcais de dominação e centralização do poder. (SILIPRANDI, 2009. p. 92)

Defende Shiva, que a principal falha consiste no paradigma desenvolvimentista que excluiu as mulheres de seus papéis de protagonistas na agricultura. $\mathrm{O}$ conhecimento que era ecológico, com uma visão global, foi desperdiçado em nome da privatização dos lucros e da exploração ambiental que tem como modelo a predatória monocultura.

Suas principais características são a postura crítica contra a dominação, a luta antisexista, a antirracista, a antielitista e a antiantropocêntrica. Vandana Shiva confere ao princípio da cosmologia a tendência protetora das mulheres para com a natureza. (SILIPRANDI, 2000. p. 69) 
No ecofeminismo clássico, a denúncia feita pelo feminismo é dirigida para a naturalização da mulher como um dos mecanismos de legitimação do patriarcado.

Neste contexto, há uma oposição da ética feminina de proteção dos seres vivos à essência agressiva masculina e está se fundamenta por meio de características igualitárias, como também por atitudes maternais que acabam pré-dispondo as mulheres ao pacifismo e à conservação da natureza. (ANGELIN, 2014, p.1583).

Já a terceira corrente é a do ecofeminismo construtivista o qual não se identifica nem com o essencialismo, nem com as fontes religiosas e espirituais, inobstante ao fato de compartilhar ideias como o antiantropocentrismo e o anti-imperialismo. (PULEO, 2004, p. 23)

Contudo, possui como fundamento que a relação profunda da maioria das mulheres com a natureza não está associada às características próprias do sexo feminino, mas é originária de suas responsabilidades de gênero na economia familiar, criadas através da divisão social do trabalho, da distribuição do poder e da propriedade. (PULEO, 2004, p. 23)

É baseado na necessidade de as mulheres assumirem novas práticas de relações de gênero e com a natureza.

Tudo se reduz a tomar medidas práticas de conservação do ambiente, que se apoiem no saber tradicional das mulheres rurais, substituir a monocultura industrial pela diversidade de sementes autóctones, descentralizar e propiciar a participação dos grupos desfavorecidos na tomada de decisões. (PULEO, 2004, p. 28)

Assim, nessa linha de ecofeminismo construtivista, o empoderamento da mulher, no âmbito da agricultura familiar, faz dela precursoras de medidas de proteção e de sustentabilidade ambiental.

Nesse viés, é de grande valia o presente estudo, que propõe a análise dos fatores que motivam as mulheres a protegerem o ambiente rural familiar, identificando, se o empoderamento desta mulher é forma de precaução ao dano ambiental por meio da formação de uma consciência ecológica e sustentável

Assim, questiona-se se estariam essas mulheres, agricultoras em regime de economia familiar, através do seu empoderamento feminino e sua sensível ligação com o ambiente, não só minimizando os riscos ambientais, como também tomando medidas de sustentabilidade; sendo referidas medidas, meios de precaução ao dano. 


\section{PRECAUÇÃO AO DANO AMBIENTAL}

A maioria das questões referentes ao ambiente está relacionada com o risco e são resultado da expansão da ciência, da tecnologia, evoluções necessárias para a manutenção da sociedade.

Desta forma, o desenvolvimento dos recursos tecnológicos, científicos, industriais e o próprio processo de industrialização, estão ligados profundamente ao processo de produção de danos, diante da exposição da humanidade a possibilidades de serem contaminadas de inúmeras formas.

Referidos riscos estão presentes a todo o momento, na sociedade e no próprio ambiente, podendo ser citado a exemplo o desmatamento acelerado, o uso irrestrito dos recursos hídricos, a biotecnologia, dentre inúmeros outros.

As mulheres são as mais atingidas por referidos danos ambientais, pois estão na frente das famílias, em uma situação de vulnerabilidade, como assevera Anne Bonewit:

O estudo "The Gender Dimension of Climate Justice" (Anne Bonewit, 2015) mostra que no fenômeno de alterações climáticas as mulheres são as mais afetadas, visto que são maioria na população representada por pessoas em situação de pobreza, reduzindo assim suas possibilidades e de suas famílias de diminuir e amenizar as consequiências no processo de alterações climáticas. Visto que o nível de desigualdade em países em desenvolvimento tende a ser maior, mulheres são ainda mais vulneráveis em tais contextos, um dos motivos é a disparidade no acesso a recursos, educação, e oportunidades de trabalho comparadas aos homens. Outro fator que vai de encontro a esses dados, é que mulheres também representam maioria na posição de chefes de famílias, responsáveis assim, pelo fornecimento de comida e todas as necessidades do núcleo familiar. (BONEWIT 2015, p. 06, apud MOURO, 2015, p. 37)

Fato que desde a revolução industrial a ideia de desenvolvimento, já estava ligada a exploração ambiental, nesse sentido expõe a visão de Adam Smith, quando afirma que a riqueza, ou valor econômico, é criada pelo trabalho, ou seja, pela transformação de recursos da natureza em coisas que as pessoas querem. (SMITH, 1988, p. 22)

Assim, a transformação da sociedade, sempre esteve ligada a necessidade de exploração do ambiente ao máximo, fato que traduz a necessidade de assumir riscos.

O risco é um dos efeitos da transformação dos modelos tecnológicos e de produção que caracterizam a sociedade moderna. 
Em verdade, o tema do risco tornou-se objeto de interesse e preocupação da opinião pública, quando o problema da ameaça ecológica permitiu a compreensão de que a sociedade produzia tecnologias que poderiam gerar danos incontroláveis

Muitas são as definições e perspectivas nas quais se analisa o risco, no âmbito da sociedade moderna, apesar das diferentes concepções e enfoques na construção do sentido do risco, este não está circunscrito a uma única dimensão da realidade, mas exprime toda a complexidade da sociedade moderna em seus diferentes embates.

O risco integra a tentativa permanente de orientar-se para o futuro, pelo desvelamento hipotético de eventualidade e contingência, com inerente indagação sobre o manejo e controle do risco, pois toda e qualquer estratégia de gerenciamento é fonte geradora de novos riscos

Na visão de Luhmann, a definição do risco baseia-se na distinção entre risco e perigo. Tal distinção pressupõe a existência de incertezas de danos futuros: evidencia-se o risco quando um dano provável é consequência da ação (de uma decisão individual ou coletiva) e está pressuposto a consciência deste dano; já o perigo indica que o dano é provocado exteriormente (atribuído à natureza), escapando ao controle. (CAPELLARI, 2016, p. 122).

A sociedade moderna está inserida num contexto em que as ações e as decisões estão implicadas na relação de probabilidade/improbabilidade dos acontecimentos, sobre os quais é difícil construir uma cadeia de conexões imputando-lhes causalidade.

Assim, a sociedade moderna é caracterizada pela sua grande capacidade de controlar as indeterminações e, do mesmo modo, de produzi-las e que tal paradoxo traz a necessidade de proteção e de segurança. Essa necessidade de segurança, todavia, está inserida num contexto de incerteza, pois toda decisão poderia ter sido tomada de forma diversa. (CAPELLARI, 2016, p. 117)

Dessa forma, Luhmann, (1992, p. 74, apud CAPELLARI, 2016, p. 120), assevera que “[...] não existe nenhuma conduta livre de risco [...] isto significa que não existe a absoluta seguridade [...] os riscos são inevitáveis quando tomamos decisões."

Nesse viés, o desenvolvimento está ligado a produção de inúmeros riscos, os quais são inerentes ao processo de evolução, não havendo conduta que seja absolutamente livre de dano, ou totalmente segura. 


\section{EMPODERAMENTO DA MULHER COMO MEIO DE SUSTENTABILIDADE}

O conhecimento por meio do empoderamento feminino faz com que a mulher tome decisões que venham de encontro com a sustentabilidade, assuma os riscos inerentes a atividade ambiental desenvolvida em suas propriedades rurais, na finalidade de garantir o sustento de sua família, tirando do meio rural somente o necessário, de forma equilibrada e consciente.

Essa ideia de que empoderar-se é um meio de libertação, também é um grande fator de desenvolvimento, tornando o principal legado para a humanidade. Ele trouxe o lado social nos debates econômicos, colaborando com novos pontos de vista na análise do desenvolvimento das nações.

No entanto, observa-se que a realização das pessoas é influenciada por oportunidades econômicas, liberdades políticas, poderes sociais e por condições habilitadoras, como boa saúde, educação básica, incentivo e aperfeiçoamento de iniciativas.

Empoderar é liberdade e indica que as medidas de desenvolvimento não podem ser baseadas somente em fatores econômicos como o Produto Interno Bruto - PIB, nas rendas das famílias, índices de consumo e industrialização.

Um tema nada novo, mas que vem se tornando recorrente em todas as esferas sociais, muitas vezes com certa confusão sobre o seu real significado, leva a crer que ainda há muito que esclarecer em termos de conceituação do tema empoderamento feminino.

Estudos da Organização das Nações Unidas (ONU) indicam que além de justiça social, o empoderamento da mulher do campo pode representar um aumento de $30 \%$ na produção agrícola e garantir a segurança alimentar do planeta.

Assegurar a inclusão dos talentos, habilidades, experiências e energia das mulheres requerem ações afirmativas e políticas públicas. Políticas públicas tem importante papel de estimular o pensamento crítico sobre as práticas de promoção da igualdade entre homens e mulheres no meio rural, servindo de instrumento para combate às desigualdades de gênero no campo.

Inicialmente as políticas eram concentradas em uma busca para obter um tratamento melhor, um tratamento mais justo, a concentração era mais sobre bem-estar do que um 
empoderamento de direitos e garantias. As mulheres evoluíram e se fortaleceram, para incorporar o papel ativo como condição de agente das suas vontades.

Agora já não mais receptoras passíveis de auxílio para melhorar seu bem-estar, as mulheres são vistas cada vez mais, tanto pelos homens como por elas próprias, como agentes ativos de mudança: promotoras dinâmicas de transformação sociais que podem alterar a vida das mulheres e dos homens. (SEN, 2017, p. 246)

A pauta feminina deve ser então, de forma urgente, a de se tornar um ser humano capaz de promover as mudanças e remover as iniquidades que restringem o bem-estar feminino.

Toda essa mudança na abordagem do papel da mulher na sociedade se deve ao potencial das mulheres de produzir, ter sua própria renda, desenvolver uma carreira profissional, e tomar decisões dentro e fora do âmbito familiar.

Percebe-se que todos esses aspectos têm em comum é a contribuição positiva para fortalecer a voz ativa e a condição de agente das mulheres, por meio da independência e do ganho de poder.

Todavia essa condição conquistada por meio de séculos de luta, não pode esmorecer frente às inúmeras batalhas que ainda estão no caminho. Muitas ainda são as desigualdades impostas pela sociedade patriarcal, cabendo a mulher o papel de agente fomentador de seus direitos, por meio de empoderamento e conhecimento.

Esses diversos aspectos da situação feminina (potencial para auferir rendimentos, papel econômico fora da família, alfabetização e instrução, direitos de propriedade etc.) podem, à primeira vista, aparecer demasiadamente variados e dispares. Mas o que todos eles têm em comum é sua contribuição positiva para fortalecer a voz ativa e a condição de agente das mulheres - por meio da independência do ganho do poder. (SEN, 2017, p. 249)

O papel da mulher e o seu poder feminino, refletido na independência econômica e emancipação social, pode ter grandes projeções sobre as forças e os princípios organizadores que governam as divisões dentro da família e na sociedade.

Deste modo, o empoderamento da mulher faz dela uma voz ativa, que influencia na família, na criação dos filhos, nas discussões públicas sobre os mais variados temas ambientais e sociais, e, principalmente, nas medidas de sustentabilidade aplicadas a propriedade. "A voz da mulher e a voz da natureza têm sido silenciadas no patriarcado. 
Mulher e natureza são consideradas objetos. Objetos não falam. Objetos não sentem. Objetos não têm necessidades. Objetos só existem para servir às necessidades dos outros." (ROSENDO, 2012, p.71).

Sua voz ativa deixa de ser somente um grito e passa ter força ativa concreta na aplicação de medidas de proteção ao ambiente, por meio do uso adequado da propriedade rural, buscando tirar dela o necessário.

A obstrução da liberdade de participar do mercado de trabalho é uma das maneiras a sujeição e ao cativeiro da mão de obra, e a batalha contra a privação de liberdade existente no trabalho. (SEN, 2017, p. 22)

Aspectos culturais podem influenciar características sociais como a igualdade entre os sexos, a natureza dos cuidados dispensados aos filhos, o tamanho da família e os padrões de fecundidade, o tratamento do meio ambiente e muitas outras.

A privação de liberdade econômica pode gerar a privação de liberdade social, assim como a privação de liberdade social ou política pode, da mesma forma gerar a privação de liberdade econômica (SEN, 2017, p. 23).

O desenvolvimento sustentável obedece ao duplo imperativo ético da solidariedade comas gerações presentes e futuras, e exige a explicitação de critérios de sustentabilidade social e ambiental e de viabilidade econômica.

O desenvolvimento, distinto do crescimento econômico, cumpre esses requisitos, na medida em que os objetivos do desenvolvimento vão além da mera multiplicação da riqueza material, o crescimento é uma condição necessária, mas de forma alguma suficiente (muito menos é um objetivo em si mesmo), para alcançar a meta de uma vida melhor, mais feliz e mais completa para todos. (SACHS, 2004, p.13)

O modelo padrão de desenvolvimento sustentável está descrito no tripé chamado de triple Botton Line (a linha das três pilastras), que deve garantir a sustentabilidade. "Para ser sustentável desenvolvimento deve ser economicamente viável, socialmente justo ambientalmente correto.” (BOFF, 2012, p. 43).

Desta forma tem-se que a ideia de desenvolvimento implica a expiação e a reparação de desigualdades passadas, criando conexões capazes de preencher o abismo civilizatório entre as minorias ricas modernizadas e a maioria ainda atrasada e exausta. (SACHS, 2004, p. 14).

Mais que sustentabilidade ambiental, necessário se faz a sustentabilidade social. 
Na visão de Leonardo Boff (2012, p. 57), “a sustentabilidade de uma sociedade se mede por sua capacidade de incluir a todos e garantir-lhes os meios de vida suficiente e decente".

Só a partir disso podemos pensar em políticas equitativas e abrangentes que corroborem para o empoderamento das mulheres. (SILIPRANDI, 2000, p.72).

Mesmo a mulher ocupando grande parte da mão de obra no setor agrícola, seu trabalho ainda é invisível e sem esse reconhecimento e as particularidades que são necessárias, respeitando as questões de gênero, não se pode pensar em sustentabilidade.

\section{CONCLUSÕES}

A mulher desde os tempos paleolíticos esteve ligada à agricultura, cultivando a terra e mantendo com ela uma relação simbiótica de produção e reprodução. Dentro do contexto social, tem-se que no decorrer da história as mulheres têm desenvolvido uma relação de cuidado com o ecossistema, de forma muito mais sensível do que os homens.

O tema proposto para estudo e pesquisa vem de encontro com a evolução da figura da mulher no âmbito das propriedades de economia familiar e o papel desempenhado por elas.

Grande parte das propriedades rurais de economia familiar é cultivada por mulheres, com a produção de variados tipos de cultura, que representam uma renda acessória a família, seja em vários casos como a fonte primaria de sustento.

São essas mulheres que estão diretamente ligadas às medidas de sustentabilidade e a produção de vários produtos nas pequenas áreas agrícolas.

As contribuições do estudo são norteadas no empoderamento da mulher agricultora, no seio da economia familiar, na finalidade de que através do conhecimento da sua relação com o ambiente estas venham a desenvolver atividades de sustentabilidade, no âmbito de suas propriedades.

Não só no sentido de preservação ambiental, como também a exploração da propriedade de forma sustentável e consciente, como por exemplo, a implantação de quintais agroflorestais.

Referidas medidas de sustentabilidade traz uma verdadeira concretização da precaução e fomento ao desenvolvimento sustentável, o que vem de encontro ao anseio da sociedade moderna no que diz respeito aos riscos ambientais. 
Além da proteção ao ambiente natural, a sustentabilidade ambiental envolve a sensação de bem-estar e de felicidade individual e coletiva. Tal sensação no, entretanto, não se dá no abstrato, mas nas possibilidades reais de atendimento das necessidades, materiais e não materiais, sentidas pelos membros da coletividade.

Assim, uma concepção adequada de desenvolvimento deve ir muito além da acumulação de riqueza e do crescimento, deve estar relacionado, sobretudo com a melhora da vida e das liberdades individuais.

Diante disso, ao constatar que o risco existe e deve ser evitado, minimizado, tratado por meio de medidas de segurança, as concepções jurídicas em torno de questões relacionadas ao risco, em especial ao risco ambiental, passam a tomar novas formas, e serem analisadas sob outros enforque, como o ecofeminismo.

$\mathrm{E}$ as ações oriundas das mulheres que laboram em seus ambientes rurais estão em estreita sintonia com a sustentabilidade do ambiente. Sendo, todavia, necessário a inclusão da análise da precaução, na finalidade de garantir a sustentabilidade e por consequência uma efetiva proteção ambiental.

As mulheres precisam independente da sua condição de gênero feminino pensar propostas que visem uma sustentabilidade, posto que, possuem particularidades e porque em resultado da sua vivência socialmente e historicamente construída, podem ofertar pontos de vistas que o pensamento masculino não consegue abranger.

Deste modo, tem-se que o ponto de partida para analisar a relação entre ecofeminismo e a sustentabilidade ambiental, no âmbito da agricultura familiar, nasce do pressuposto de que a existência de práticas sustentáveis está no seio da organização. Sendo a mulher nesse vetor forma natural de sustentabilidade, por meio do princípio da precaução.

As discussões acerca do ecofeminismo e do papel desempenhado pela mulher no ambiente rural, como vetor de sustentabilidade ainda são parcas, em especial no sentido de seu empoderamento, quanto conhecedora das atividades que podem desenvolver no âmbito da sua propriedade como fonte de renda e medida de proteção ecológica.

A maioria das pesquisas, desenvolvidas na área de sustentabilidade, estão voltadas para a natureza, produção, minimização de danos ambientais, situações ligadas a agroecologia com o enfoque a sustentabilidade; havendo necessidade da análise do tema proposto, que buscou o estudo sob outro viés, o da questão social vindo a incluir o estudo da sustentabilidade sob a ótica das mulheres. 


\section{REFERÊNCIAS BIBLIOGRÁFICAS}

ANGELIN, Rosângela. Gênero e Meio Ambiente: a atualidade do Ecofeminismo. Revista Espaço Acadêmico, n. 58, mar. 2006. Disponível

em: $\langle$ https://siaiap32.univali.br/seer/index.php/rdp/article/view/6751 $>$. Acesso em: 10 out. 2020.

ANGELIN, Rosângela. Mulheres, ecofeminismo e desenvolvimento sustentável diante das perspectivas de redistribuição e reconhecimento de gênero. Estamos preparados?. Revista Eletrônica Direito e Política, n.3, v.9, jul/dez. 2014. Disponível em:

<file:///C:/Users/Acer/Downloads/6751-18251-1-SM.pdf> Acesso em: Acesso em: 10 out. 2020.

BECK, Ulrich. Sociedade de risco: rumo a uma outra modernidade. Trad. de Sebastião Nascimento. São Paulo: Editora 34, 2010.

BOFF, Leonardo. Ética da vida: a nova centralidade, $1^{\text {a }}$. ed. Rio de Janeiro: Record, 2009.

Saber cuidar: Ética do humano - compaixão pela terra. $1^{\text {a }}$. ed. Rio de Janeiro: Vozes, 2017.

Sustentabilidade. O que é - O que não é?. 4ª ed. Rio de Janeiro: Vozes, 2015.

BRASIL. Constituição (1988). Constituição da República Federativa do Brasil. Brasília, DF: Presidência da República, 2014.

CAPELLARI, Marta Botti. O princípio da precaução como forma de aquisição evolutiva da sociedade moderna diante dos riscos ambientais. $206 \mathrm{f}$. Tese (Doutorado em Direito) Programa de Pós-Graduação em Direito. Universidade Federal do Paraná, Curitiba, 2016. 
CIOMMO, Regina Célia Di. Relações de gênero, meio ambiente e a teoria da complexidade.

Revista Estudos Feministas, n.2, v.11, jul/dez. 2003. Disponível em: <

http://www.scielo.br/scielo.php?script=sci_arttext\&pid=S0104-

026X2003000200005\&lng=en\&nrm=iso\&tlng=pt $>$ Acesso em: 10 out. 2020.

FREIRE, Paulo. Pedagogia do oprimido. 50. ed. Rio de Janeiro: Paz e Terra, 2011.

GIL, Antonio Carlos. Como elaborar projetos de pesquisa. 5. ed. São Paulo: Atlas, 2010.

GIORGI, Raffaele de. Direito, democracia e risco: vínculos com o futuro. Porto Alegre: Sergio Antônio Fabris Editor, 1998.

LAKATOS, Eva Maria; MARCONI, Marina de Andrade. Metodologia do trabalho científico. 7. ed. São Paulo: Atlas, 2012.

MENDONÇA, Rafael, A Filosofia Ecofeminista Holística De MartiKheel, Revista Fazendo Gênero: Diáspora, diversidade e deslocamentos, apud KHEEL, Marti. From Heroic to Holistic Ethics: The Ecofeminist Challenge, p. 211

MILARÉ, Édis. Direito do ambiente: doutrina, jurisprudência, glossário. $5^{\text {a }}$. ed. São Paulo: Revista dos Tribunais, 2007.

MOURO, Higor Henrique. Gênero e Ambiente: Reflexões sobre o papel da mulher na questão socioambiental. 106 f. Dissertação (Mestrado em Ecologia Humana e Problemas Sociais Contemporâneos) - Pós-Graduação em ciências sociais e humanas. Universidade Nova de Lisboa, Lisboa. 2017

PULEO, Alicia H. Mulher, Feminismo e ecologia. Revista Eco 21. V. 01, Ed. 97. Disponível em: 〈http://www.eco21.com.br/textos/textos.asp?ID=982〉. Acesso em 13 out. 2020.

ROSENDO, Daniela. Sensível ao Cuidado Uma Perspectiva Ética Ecofeminista. $1^{\text {a }}$ ed. Rio de Janeiro: Garamond, 2008. 
SACHS, Ignacy. Desenvolvimento includente, sustentável sustentado. $1^{\text {a }}$. ed. Rio de Janeiro: Garamond, 2008.

SEN, Amartya. Desenvolvimento como liberdade. 6a. ed. São Paulo: Companhia de Bolso, 2017.

SHIVA, Vandana. 1991. Abrazar la vida: mujer, ecologia y super vivencia. Trad. Ana E. Guyere Beatriz Sosa Martinez. Montevideo: Instituto del Tercer Mundo.

SILIPRANDI, Emma. Ecofeminismo: contribuições e limites para a abordagem de políticas ambientais. Agroecologia e Desenvolvimento Rural Sustentável, v.1, n.1, jul/dez. 2000. Disponível em: 〈http://www.emater.tche.br/docs/agroeco/revista/n1/11_artigo_ecofemi.pdf $>$. Acesso em 13 out. 2020.

SILIPRANDI, Emma. Mulheres e Agroecologia construção de novos sujeitos políticos na agricultura familiar. 292 f. Tese (Doutorado em Direito) - Programa de Pós-Graduação em Desenvolvimento Sustentável. Universidade de Brasília, Brasília, 2009.

SMITH, Adam. "A Riqueza das Nações", volume I, Nova Cultural, 1988, Coleção "Os Economistas", pág. 17-54. 